\title{
Congenital hypothyroidism
}

Azyan Shafeek ${ }^{1}$, Stella G de Silva ${ }^{2}$

Sri Lanka Journal of Child Health, 2001; 30: 48

(Key words: Congenital hypothyroidism)

This five month old child was brought from Trincomalee on 8th February 2001 for poor feeding and failure to gain weight. She was the second child of non-consanguineous parents born on 18th October 2000, female, normal delivery, birth weight $3.38 \mathrm{~kg}$. The older child was normal. The father, a postmaster, had consulted many doctors of his neighbouring districts.

On examination she weighed $4.7 \mathrm{~kg}$ (at five months) was inactive, lethargic with poor head control. She had coarse facies, a hoarse voice, dry skin, an umbilical hernia (Figure 1). She was constipated. A clinical diagnosis of hypothyroidism was made. This was supported by TSH $112 \mathrm{mlU} / \mathrm{L}$ (normal for age $0.7-6.4 \mathrm{mlU} / \mathrm{L}$ ) T4 $0.01 \mathrm{ng} / \mathrm{dl}$ (normal for age $0.9-2.6 \mathrm{ng} / \mathrm{dl}$ ) Bone age of a new born (at age five months) $\mathrm{Hb} 8.9 \mathrm{~g} / \mathrm{dl} \mathrm{ECG}$ was normal.

She was admitted to Durdans Hospital for initiating therapy with thyroxin, starting with a small dose. She was discharged on $25 \mathrm{ug}$ daily with instruction to constant supervision, measurement of TSH and life long thyroid hormone replacement.

She was reviewed on 16th March 2001. She weighed $5.40 \mathrm{~kg}$; skin was smooth.

Since this child was recognized late her future mental development is uncertain but the physical development should be good.

${ }^{1}$ House Officer (Paediatric Unit), Durdans Hospital, Colombo, ${ }^{2}$ Consultant Paediatrician

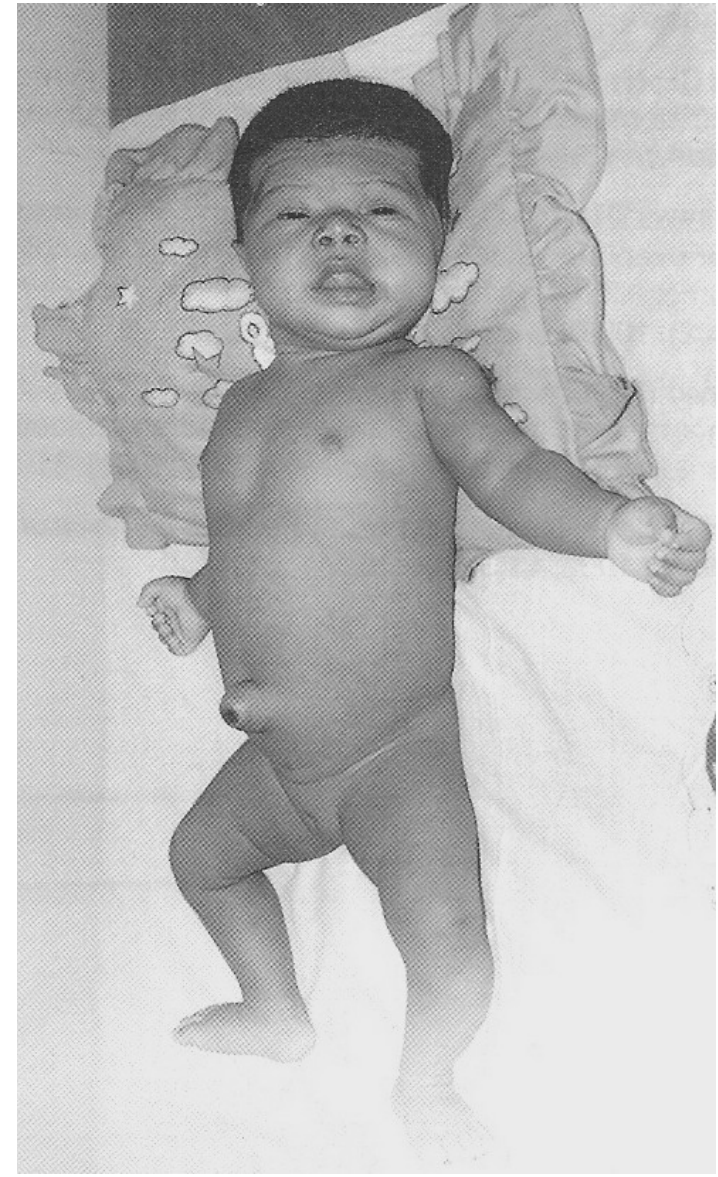

Figure 1 Hypothyroid baby aged five months 